\title{
THERMAL OPERATING MACHINE
}

\section{GIUSEPPE VERDE}

Student at Parthenope University of Naples, Italy

\begin{abstract}
A thermal machine with reverse cycle and steam compression and its operating method are described; the machine comprises: a condenser (2) downstream of and in fluid communication with a main compressor (6) with includes a connection to a thermoelectric generator (13r) based on the Seebeck effect; a main lamination valve (9) downstream of the condenser (2); an evaporator (10) downstream of and in fluid communication with the lamination valve (9); an electric generator (13); an electric charge accumulator (15, 17); an automatic time-changing switch (14) configured depending on hourly production and consumption slots of an electric market, connected downstream of the electric generator (13) and before the accumulator (15,17); at least one expander (7) connected to at least one alternator (8) in fluid communication between the evaporator (10) and the main compressor (6); and at least one heat exchanger (5) having a hot branch connected downstream to the condenser (2) and before the lamination valve (9) and a cold branch connected downstream to a second lamination valve (4) and upstream to the expander (7);characterized in that the alternator (8) includes a connection to a thermoelectric generator (13r) based on the Seebeck effect.

KEYWORDS: Expander, Alternator, Lamination Valve, Electric Charge Accumulator \&Automatic Time-Changing Switch
\end{abstract}

Received: Aug 19, 2017; Accepted: Sep 07, 2017; Published: Oct 04, 2017; Paper Id.: IJMPERDOCT201732

\section{INTRODUCTION}

This research refers to an extension of the study conducted for a thermal operating machine [1] characterized that it comprises a heat dissipation recovery system [2], mainly to the compressor. The use of a thermal operating machine capable of performing its function following a process, which continuously requires an adequate sustainable development, is known.

Otherwise, this can cause several problems, such as the continuous use of energy sources deriving from resources, which tend to be exhausted in the human time scale, namely fossil fuels such as oil and natural gas, becoming too costly or too polluting for the environment, such as the production of greenhouse gases or radioactive waste.

A first object of the present research is providing a system [3] which, by cyclically operating and absorbing energy as work, has no inconveniences of the above cited known systems and is particularly simple and comfortable.

Another object of the invention is providing an efficient and reliable system, having a simple structure to make, capable of favouring energy savings without using obnoxious or damaging materials, capable of interfering with natural operating mechanisms of the ecosystems and of impairing the quality of life.

The main inefficiency in a common thermal operating machine is the expansion valve [4], which allows passing the refrigerating liquid from hit pressure to low pressure without using the available potential energy. 
Figure (a) shows the corresponding diagram p-h (pressure-enthalpy) of a traditional plant.

p-h diagramm of a traditional system

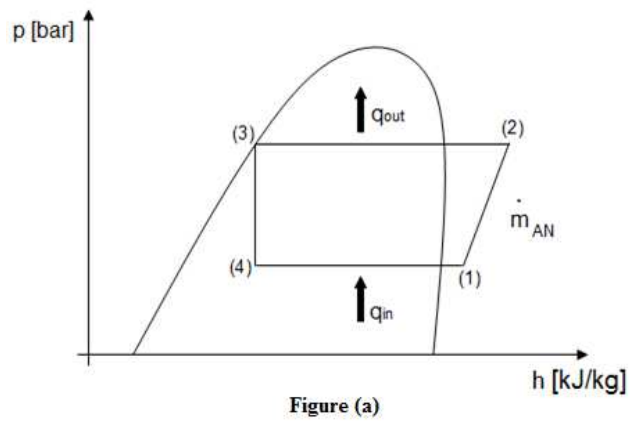

Starting from this consideration we have tried to use all available energy from the refrigerating liquid, increasing the process efficiency. Table 1 shows the thermodynamic parameters of a traditional system.

Table 1: Thermodynamic Parameters of a Traditional System

\begin{tabular}{|c|c|c|c|c|}
\hline Thermodynamic State & $\mathbf{P}[\mathbf{b a r}]$ & $\mathbf{T}\left[{ }^{\circ} \mathbf{C}\right]$ & $\mathbf{s}[\mathbf{k J} / \mathbf{k g K}]$ & $\mathbf{h}[\mathbf{k J} / \mathbf{k g}]$ \\
\hline 1 & 1,04 & $-40,00$ & 1,66 & 344,40 \\
\hline 2 & 20,59 & 110,30 & 1,81 & 461,90 \\
\hline 3 & 20,59 & 45 & 1,23 & 268,10 \\
\hline 4 & 1,04 & $-45,27$ & 1,32 & 268,10 \\
\hline
\end{tabular}

\begin{tabular}{|c|r|}
\hline Coefficient of Performance & 0,65
\end{tabular}

These and other objects are obtained according to the present invention through a heat exchanger which is inserted downstream of a condenser and before a thermostatic valve, part of the refrigerating liquid going out of the condenser is switched to this heat exchanger, from which part of the heat is recovered to produce gas, through which a turbine connected to an alternator is operated, which recovers and collects useful kinetic energy, extracting it from an amount of what is normally, according to the current prior art, dispersed into thermal energy, thereby negatively affecting the performance coefficient of the plant.

Table 2 shows the thermodynamic results with reference to the parameters of Table 1. Table 3 shows the annual energy consumption with the relative cost and the amount of $\mathrm{CO}_{2}$ emitted of a traditional plant.

Table 2: Energy Values of a Traditional System

\begin{tabular}{|c|c|c|}
\hline Calculated Value & Equation & Result \\
\hline $\begin{array}{l}\text { Mechanical power of the } \\
\text { compressor }\end{array}$ & LGAN $=\dot{m}_{A N} \cdot\left(h_{2 ; A N}-h_{1 ; A N}\right)$ & $46,20 \mathrm{~kW}$ \\
\hline $\begin{array}{l}\text { Electric power of the } \\
\text { compressor }\end{array}$ & PEAN $=\frac{\text { L'CAN }}{\text { TifuEl }}$ & $47,63 \mathrm{~kW}$ \\
\hline Dissipated electricity & $Q_{\mathrm{dISB} ; A N}=$ PEAN - LICAN & $1,43 \mathrm{~kW}$ \\
\hline Refrigeration Power & $\left(h_{1 ; A N}-h_{4 ; A N}\right)$ & $30,00 \mathrm{~kW}$ \\
\hline $\begin{array}{l}\text { Coefficient } \\
\text { Performance(COP) }\end{array}$ & COPAN $=\frac{\text { GeVAN }}{\text { LCAN }}$ & 0,65 \\
\hline
\end{tabular}

Table 3: Energy Consumption and $\mathrm{CO}_{2}$ Emissions of a Traditional System 


\begin{tabular}{|c|c|c|}
\hline Calculated Value & Equation & Result \\
\hline $\begin{array}{ll}\text { Annual } & \text { energy } \\
\text { consumption } & \end{array}$ & $\mathrm{CE} B \mathrm{AN}=\mathrm{PEAN} \cdot \mathrm{FmC}$ & $208609 \frac{\mathrm{kWh}}{\text { Anno }}$ \\
\hline Annual energy taxable & 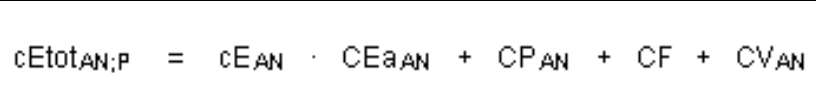 & $30382 \frac{€}{\text { Anno }}$ \\
\hline Tax at $22 \%$ & WAN $=$ EEtotaN;P $\cdot \frac{22}{100}$ & $6684 \frac{€}{\text { Anno }}$ \\
\hline Annual energy cost & Etotan $=$ cEtotAN;P + WAAN & $37066 \frac{€}{\text { Anno }}$ \\
\hline $\mathrm{CO}_{2}$ equivalent & $\mathrm{Co}_{2: \mathrm{eq} ; \mathrm{AN}}=\frac{\mathrm{GMN}_{100 \mathrm{anni}}}{100}$ & $1883 \frac{\mathrm{kg}}{\text { Anno }}$ \\
\hline Min. emission $\mathrm{CO}_{2}$ & $\mathrm{co}_{2 ; \mathrm{min} ; \mathrm{AN}}=\frac{\mathrm{cO}_{2}}{\mathrm{WWh}} \cdot$ PeAN $\cdot$ OreFA $+\mathrm{co}_{2 ; \mathrm{eq} ; \mathrm{AN}}$ & $26152 \frac{\mathrm{kg}}{\mathrm{Anno}}$ \\
\hline Max. emission $\mathrm{CO}_{2}$ & $\mathrm{CO}_{2 ; \mathrm{max} ; \mathrm{AN}}=\frac{\mathrm{CO}_{2}}{\mathrm{WWh}_{\mathrm{W}}} \cdot \mathrm{CEa,AN}+\mathrm{CO}_{2 ; \mathrm{eq} ; \mathrm{AN}}$ & $75397 \frac{\mathrm{kg}}{\text { Anno }}$ \\
\hline
\end{tabular}

Such part of useful residual energy deriving from the exhaust gases, which produces a mechanical power used to move the turbine and actuate the alternator, is transformed into electric energy, which is moderately reproduced after every cycle of use, and at a regeneration rate necessary and adequate to improve the useful effect coefficient of the plant. Table 4 shows the thermodynamic parameters of the proposed system.

Table 4: Thermodynamic Parameters of a Nominal Conditions According to the Present Invention

\begin{tabular}{|c|c|c|c|c|c|}
\hline Thermodynamic State & $\dot{\mathbf{m}}_{[\mathbf{k g} / \mathbf{s}]}$ & $\mathbf{P}[\mathbf{b a r}]$ & $\mathbf{T}\left[{ }^{\circ} \mathbf{C}\right]$ & $\mathbf{s}[\mathbf{k J} / \mathbf{k g K}]$ & $\mathbf{h}[\mathbf{k J} / \mathbf{k g}]$ \\
\hline 1 & 0,30 & 1,04 & $-40,00$ & 1,66 & 344,40 \\
\hline 2 & 0,30 & 3,75 & 25,60 & 1,74 & 394,70 \\
\hline 3 & 0,36 & 3,75 & 19,53 & 1,73 & 389,10 \\
\hline 4 & 0,36 & 20,59 & 97,14 & 1,77 & 446,90 \\
\hline 5 & 0,36 & 20,59 & 45,00 & 1,22 & 268,10 \\
\hline 6 & 0,06 & 12,60 & 25,25 & 1,23 & 268,10 \\
\hline 7 & 0,30 & 20,59 & 30,25 & 1,15 & 244,30 \\
\hline 8 & 0,30 & 1,04 & $-45,36$ & 1,22 & 244,30 \\
\hline 9 & 0,06 & 12,60 & 27,74 & 1,60 & 379,40 \\
\hline 10 & 0,06 & 3,75 & $-9,03$ & 1,63 & 363,00 \\
\hline
\end{tabular}

\begin{tabular}{|c|c|}
\hline $\begin{array}{c}\text { Coefficient of } \\
\text { Performance }\end{array}$ & 0,86 \\
\hline
\end{tabular}

The thermal operating machine (according to this research) is characterized in that the compressors $(1,6)$ and the alternator (8) includes a connection to a thermoelectric generator (13r) based on the Seebeck effect. In so doing, the generated electric energy can be stored in an accumulator and be used afterwards, for example without electric supply, obtaining the convenience and advantage of being able to use useful energy, which otherwise would have not been used. Table 5 shows the thermodynamic results with reference to the parameters of Table 4 . Table 6 shows the annual energy consumption with the relative cost and the amount of $\mathrm{CO}_{2}$ emitted of a proposed plant. 
Table 5: Energy Values of a Nominal Conditions According to the Present Invention

\begin{tabular}{|c|c|c|}
\hline Calculated Value & Equation & Result \\
\hline $\begin{array}{l}\text { Mechanical power of the } \\
\text { compressor (1) }\end{array}$ & $\dot{L}_{1}=\dot{m}_{2} \cdot\left(h_{2}-h_{1}\right)$ & $15,05 \mathrm{~kW}$ \\
\hline $\begin{array}{l}\text { Mechanical power of the } \\
\text { compressor (6) }\end{array}$ & $\dot{L}_{02}=\dot{m} \cdot\left(h_{4}-h_{3}\right)$ & $21,02 \mathrm{~kW}$ \\
\hline $\begin{array}{l}\text { Total mechanical } \\
\text { compression power }\end{array}$ & $\dot{L}_{0} T_{0 t}=i_{01}+i_{02}$ & $36,07 \mathrm{~kW}$ \\
\hline $\begin{array}{l}\text { Electric power of the } \\
\text { compressor (1) }\end{array}$ & $P e_{01}=\frac{\dot{L}_{01}}{r_{\text {fuel }}}$ & $18,13 \mathrm{~kW}$ \\
\hline $\begin{array}{l}\text { Electric power of the } \\
\text { compressor }(6)\end{array}$ & $P e_{\infty 2}=\frac{i_{02}}{r_{\text {fuel }}}$ & $21,45 \mathrm{~kW}$ \\
\hline $\begin{array}{l}\text { Total electrical } \\
\text { compression power }\end{array}$ & Peotot $=$ Peo1 $+\mathrm{Ped}_{2}$ & $39,58 \mathrm{~kW}$ \\
\hline $\begin{array}{l}\text { Mechanical expander } \\
\text { power }\end{array}$ & $\dot{L}_{t 1}=\dot{m}_{1} \cdot\left(h_{g}-h_{10}\right)$ & $1,05 \mathrm{~kW}$ \\
\hline $\begin{array}{l}\text { Electric expander power } \\
\text { (Saving electricity) }\end{array}$ & PEtTot $=\dot{L}_{t} T_{o t} \cdot$ rilfuel & $0,83 \mathrm{~kW}$ \\
\hline Total mechanical power & $\dot{L}_{\text {Tot }}=\dot{L}_{\text {otot }}-\dot{L}_{t \text { Tot }}$ & $35,01 \mathrm{~kW}$ \\
\hline Total electric power & Pe $=$ Peotot - PetTot & $38,75 \mathrm{~kW}$ \\
\hline Dissipated electric power & $\dot{Q}_{\mathrm{diss}}=$ Pestot $-\dot{L}_{\mathrm{c} T o t}+\dot{L}_{t} T_{\text {ot }}-$ PEtTot & $3,56 \mathrm{~kW}$ \\
\hline Recovered electric power & $\mathrm{P}_{\mathrm{GT}}=\dot{Q}_{\mathrm{di} s \mathrm{~s}} \cdot \eta_{\mathrm{GGT}}$ & $0,25 \mathrm{~kW}$ \\
\hline Energy recovery & $\mathrm{RGT}=\mathrm{FGT} \cdot \mathrm{Fmc}$ & $1093 \frac{\mathrm{kWh}}{\text { Anno }}$ \\
\hline Refrigeration Power & $\dot{g} w=\dot{m}_{2} \cdot\left(h_{1}-h_{s}\right)$ & $30,00 \mathrm{~kW}$ \\
\hline $\begin{array}{l}\text { Coefficient of } \\
\text { Performance (COP) }\end{array}$ & $\mathrm{OOF}=\frac{\text { gew }}{\text { LTot }}$ & 0,86 \\
\hline
\end{tabular}

$\dot{\mathrm{m}}_{1}=0,064 \mathrm{~kg} / \mathrm{s}$ e con $\dot{\mathrm{m}}_{2}=0,3 \mathrm{~kg} / \mathrm{s}$

Table 6: Energy Consumption and $\mathrm{CO}_{2}$ Emissions according to the Present Invention

\begin{tabular}{|c|c|c|}
\hline Calculated Value & Equation & Result \\
\hline Annual energy consumption & $\mathrm{CEa}=\left(\mathrm{Pe}-\mathrm{PGT}_{\mathrm{G}}\right) \cdot \mathrm{Fmc}$ & $168617 \frac{\mathrm{kWh}}{\mathrm{Anno}}$ \\
\hline Annual energy taxable & cEtotp $=\mathrm{cE} \cdot \mathrm{CEa}+\mathrm{CP}+\mathrm{cF}+\mathrm{CV}$ & $23502 \frac{€}{\text { Anno }}$ \\
\hline Tax at $22 \%$ & $\mathrm{VA}=\mathrm{cEtotp} \cdot \frac{22}{100}$ & $5170 \frac{€}{\text { Anno }}$ \\
\hline Annual energy cost & Etot $=$ Etotp + IVA & $28673 \frac{€}{\text { Anno }}$ \\
\hline $\mathrm{CO}_{2}$ equivalent & $\mathrm{co}_{2 ; e q}=\frac{G M F_{100 a n i} \cdot \mathrm{cr}}{100}$ & $1883 \frac{\mathrm{kg}}{\mathrm{Anno}}$ \\
\hline Min. emission $\mathrm{CO}_{2}$ & $c 0_{2 ; \text { min }}=0_{2 ; e q}$ & $1883 \frac{\mathrm{kg}}{\mathrm{Anno}}$ \\
\hline Max. emission $\mathrm{CO}_{2}$ & $\mathrm{co}_{2 ; \max }=\frac{\mathrm{co}_{2}}{\mathrm{Wh}_{\mathrm{h}}} \cdot \mathrm{cEa}_{\mathrm{a}}+\mathrm{co}_{2 ; \mathrm{eq}}$ & $61303 \frac{\mathrm{kg}}{\text { Anno }}$ \\
\hline
\end{tabular}


Many efforts have been made in the past to reduce the power consumed by the main compressor of the refrigerating plants. The present invention adopts a special technique based on power regeneration for internal cycles, in order to reduce the electric energy consumption. The Table 7 shows analysis of energy advantages.

Table 7: Analysis of Energy Advantages according to the Present Invention

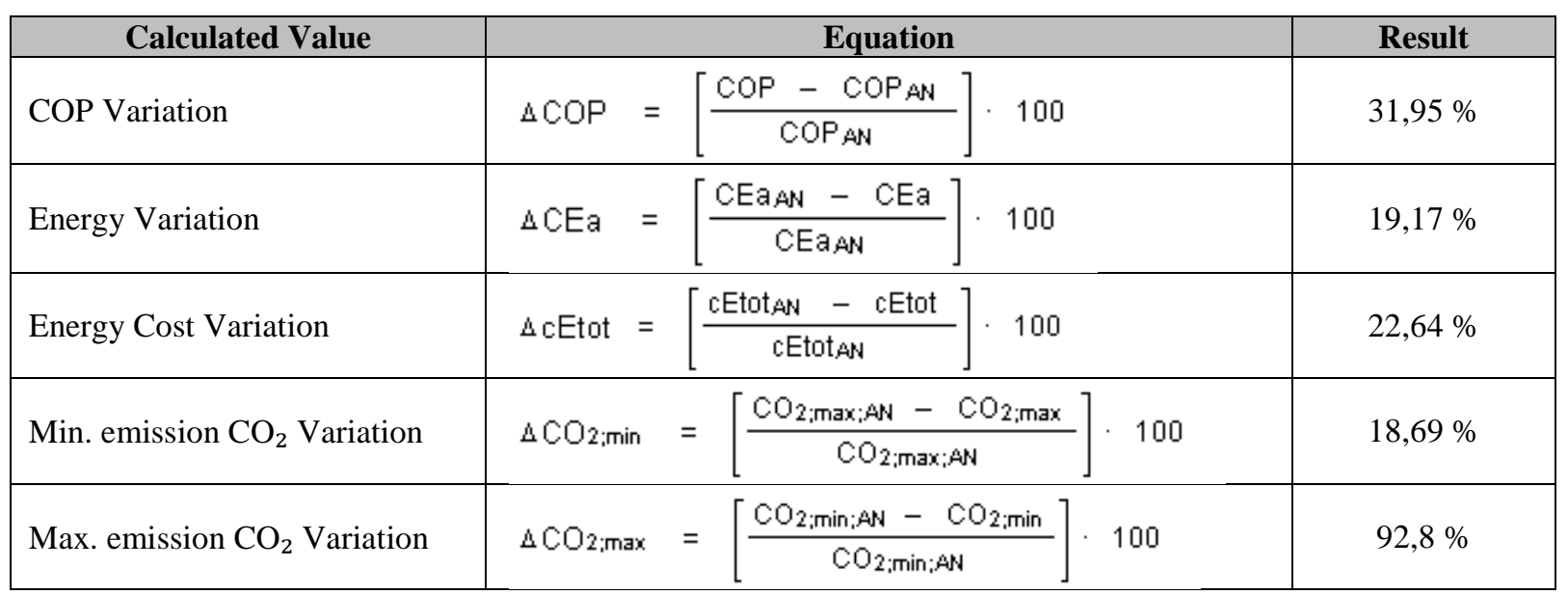

The innovation is then related to the insertion of a heat exchanger for recovering energy and of an alternator inside a conventional refrigerating plant. The application of this device allows obtaining a high improvement of plant efficiency and refrigerating capability. Both these effects increase when the operating temperature and the evaporation temperature decrease (Fig. b).

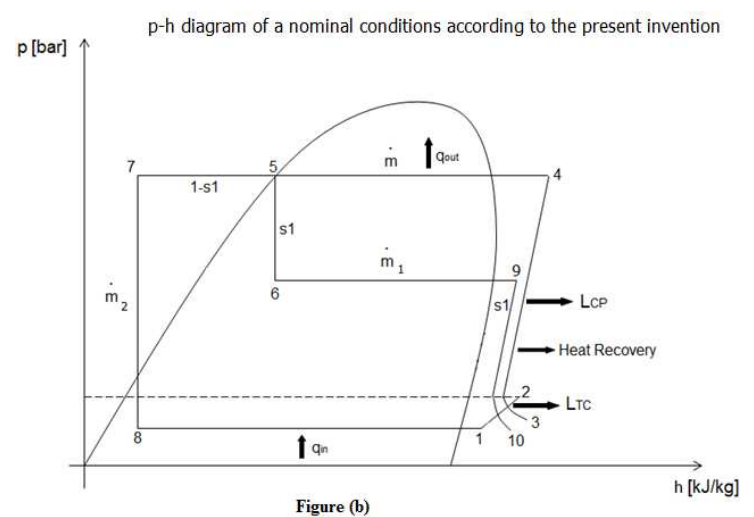

Moreover, an advantageous object of the present invention is the insertion of an electric charge accumulator, which comprises an automatic timed control system for switching the electric circuit off, which guarantees the chance of exploiting, in an ecologically convenient way, the multi-hour tariff of electric energy producing companies (Fig. f). The operation of the system of the invention consists in adopting one or more bleeds of refrigerant downstream of the condenser, which is expanded till an intermediate pressure between the operating ones through an expansion valve. The bled flow-rate is afterwards inserted in the "cold side" circuit of a heat exchanger ad hoc. The remaining part of the working fluid going out of the condenser is instead inserted in the "hot side" circuit of the additional exchanger. Due to thermal gradient existing between the two flow-rates, an under-cooling of the "hot side" fluid is enabled, together with the complete evaporation of the two-phase mixture which composed the "cold side". Steam produced by bleeding is then inserted in an expander connected to an alternator, in order to recover part of the electric energy to be given to the compressor. Moreover, the under-cooling of the remaining part of fluid enables, as known, a better refrigerating yield. 
Globally, an improvement of the performance coefficient of the plant is obtained, with consequent energy and money savings. Plants aimed to the production of industrial refrigerating energy have been mainly taken into account, comparing, from a thermodynamic point of view, a hypothetic plant using the solution of the invention and an actual plant with known prior technologies. Traditional plants with reverse cycle (Fig. c) have a substantial inefficiency given by the use of the static choking member. In fact, it makes it possible to expand with an initial enthalpy equal to the final one of the working fluid along the pressure (and therefore temperature) decreasing direction, degrading the wear pressure energy. The lamination valve is namely an economic but completely dissipative device.

\section{Manuscript file}

The features and the advantages of the present invention will clearly appear from the following detailed description of a preferred embodiments thereof, shown as a non-limiting example by the enclosed drawings, in which:

figure (c) shows the typical plant diagram of the basic operation of a prior art thermal operating machine;

figure (d) shows the basic electric diagram of a prior art thermal operating machine;

figure (e) shows the plant diagram of the basic operation of a thermal operating machine according to the present invention;

figure (f) shows the basic electric diagram of a thermal operating machine according to the present invention.

Though the invention is described with reference to an embodiment thereof, it will be clear to the skilled people in the art that it is possible to make several modification to what is described, without departing from the scope of the invention. For example, instead of using a single economizer with a single expander, it is possible to use two economizers with two expanders.

\section{Plant Art Note}

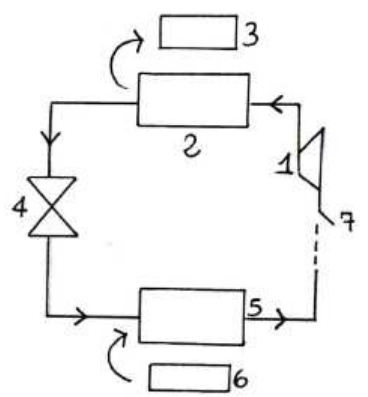

Figure (c)

The traditional plant is shown in figure (c) which is performed on a refrigerating working fluid, initially at its gaseous state, which is compressed by means of a compressor (1) e.g. Mod. FRASCOLD 5x Z30-126Y, which raises the pressure of the fluid in gaseous phase through the use of mechanical energy and, as consequence of the compression, a temperature increase occurs for the working fluid.

[5] The working fluid temperature is then lowered due to the action of a condenser (2) e.g. Mod. ONDA CN503B4AX D P 2,1 H CB GA, which takes back the working fluid to its liquid state, extracting heat spontaneously due to a thermal interaction with the environment or an outside room, which is seen as thermal energy tank (3), since the working fluid going out of the compressor (1) has a higher temperature than the ambient temperature, so that, when 
crossing the condenser (2), the working fluid takes its own temperature to a lower temperature and afterwards passes from the gaseous state to the liquid state.

Moreover, by means of a lamination valve (4) e.g. Mod. CAREL E2V35SSM00, which corresponds to a choking of the duct, pressure and temperature of the working fluid are lowered, since, during the passage by such choking, fluid at its liquid state subjected to localized load losses passes to a two-phase gas - liquid mixture. The working fluid is afterwards injected inside the evaporator (5) e.g. Mod. ONDA E503D10C100 D CB GA, due to the pressure existing in the liquid sucking side, and is then put in thermal contact with the external environment, namely with the internal room of the refrigerator (if this is a refrigerating cycle), which is seen as thermal energy tank (6), since in the evaporator (5) the working fluid, absorbing heat, returns to its low-pressure gaseous state. The working fluid at gaseous state is then taken back to the compressor (1) to start again a new thermodynamic cycle. The thermodynamic cycle is repeated many times and will be interrupted by a thermostat (7), which will take care of turning the compressor off when the pre-set temperature inside the refrigerator has been reached. The typical layout of such thermal machines provides for the use of a compressor (1), two heat exchangers $(2,5)$, through which the thermal exchange occurs with the environments $(3,6)$, and an expansion unit, for example a capillary tube or a lamination valve. The working fluids must have such physical-chemical characteristics as to make them suitable for such application, such a slow critical temperatures and pressures, high density, high latent vaporization heat, chemical stability, not dangerous and non-toxic for humans. The compressor (1) increases the steam pressure at such a level that the corresponding saturation temperature is greater than the corresponding saturation temperature is greater than the ambient temperature in which the high-pressure exchanger (2) works. In the same way, the operating pressure of the low-pressure exchanger (5) must be such that the corresponding saturation temperature is lower than the ambient temperature (6) at which the exchanger (5) itself works. Compressed steam is inserted into the highpressure exchanger (2), which, by exchanging thermal power with the environment (3), allows the fluid to condense, which is therefore taken from overheated steam to saturated or under cooled liquid. Afterwards, liquid is send to the expansion member (4) to decrease its pressure at the pre-established level. Fluid going out is finally entered into the low-pressure exchanger (5) which, receiving thermal power from the environment (6), enables the complete evaporation of the twophase mixture till saturated or overheated steam. From here, the cycle is repeated again as explained above. The basic electric diagram of a prior art thermal operating machine is shown in figure (d).

Electric diagram Art Note

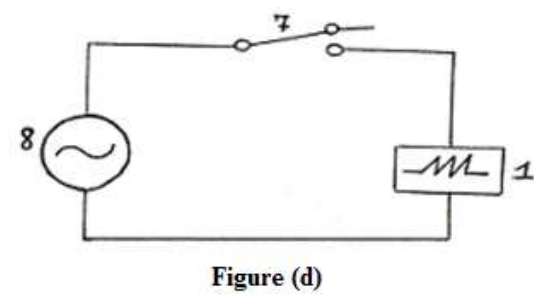

It is simply based on the use of a source aimed to transmit electricity to a voltage generator (8) to supply an electric resistor of the compressor (1). Turning the compressor (1) on and off are controlled by the thermostat (7). The basic operating diagram of a thermal operating machine according to the present invention is shown in fig. (e).

\section{Plant Proposed}




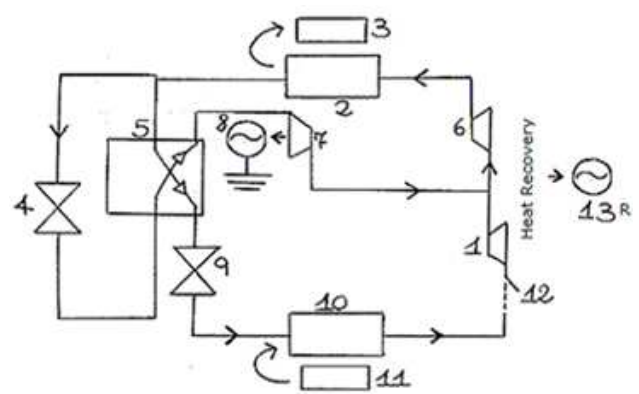

Figure (e)

It is based on the use of a thermodynamic cycle, which is performed on a refrigerating working fluid, which is initially at its gaseous state, and is slightly compressed by means of a first compressor (1), which raises the pressure of the working fluid in its gaseous phase going out the evaporator (10) through the use of necessary mechanical energy and, as consequence of the compression, an increase occurs of the temperature of the working fluid. The working fluid, which is firstly sent to the main compressor (1) e.g.Mod. FRASCOLD W75-240Y, is afterwards injected into the second compressor (6) e.g. Mod. FRASCOLD Z35-106Y, which further rises pressure and temperature of the fluid itself, by the use of mechanical energy useful and necessary for further conversion into electric energy by means of the heat dissipated by the compressors $(1,6)$; characterized in that every operating pneumofore compression machine $(1,6)$ includes a connection to a thermoelectric generator (13r) e.g. MOD. ERACON ZANIN TG-200-B, with detection through use Thermocouple J. Special Class. based on the Seebeck effect. The temperature of the working fluid is then afterwards lowered due to the action of a condenser (2) e.g. Mod. ONDA CN503B3AX D P2,1 H CB GA, which takes back the working fluid to its liquid state by extracting heat spontaneously due to thermal interaction with the environment or the outside room, which is seen as thermal energy tank (3), since the working fluid going out of the second compressor (6) has a higher temperature than the ambient temperature, so that, when crossing the condenser (2), the working fluid takes its own temperature to a lower temperature and afterwards passes from its gaseous state to its liquid state. When going out of the condenser (2), part of the liquid is bled and is subjected to a first lamination through a thermostatic valve (4) e.g. Mod. CAREL E2V24SSM00, getting cooled. Then, it enters the economizer (5) e.g. MOD. ONDA S 22-26 ECO, namely a heat exchanger, where it evaporates before entering in the second compression stage (6), subtracting heat to the remaining part of liquid coming from the condenser (2), under cooling it. Heat subtracted to liquid coming from the condenser (2), makes steam, produced by the economizer (5), at an intermediate pressure, be firstly sent to a turbine (7) e.g. MOD. Air Squared Expander Scroll E15H022A-A03, where the available potential energy is transformed into useful kinetic energy, which is transferred to an alternator (8) e.g. MOD. Air Squared Alternator E15H022A-SH, for a further conversion into electric energy; characterized in that the alternator (8) includes a connection to a thermoelectric generator (13r) e.g. MOD. ERACON ZANIN TG-100-B, based on the Seebeck effect with detection through use Thermocouple J. Special Class. Afterwards, the refrigerant is directly injected into the second compressor (6). Moreover, by means of a lamination valve (9) e.g. Mod. CAREL E2V35SSM00 equally used for the traditional system, which corresponds to a duct coking, pressure and temperature of the remaining part of the under cooled working fluid coming from the economizer (5) are lowered, since, during the passage from such coking, fluid at its liquid state subjected to localized load losses passes to a two-phase gas - liquid mixture. The working fluid is afterwards injected inside the evaporator (10) e.g. MOD. ONDA E503D10C100 D CB GA equally used for the traditional system, due tot the pressure existing in the liquid sucking side, and is then put in thermal contact with the external environment, namely with the internal room of the refrigerator (if this is a refrigerating 
cycle), which is seen as a thermal energy thank (11), since in the evaporator (10) the working fluid, absorbing heat, returns to its low-pressure gaseous state. The working fluid at its gaseous state is then taken back to the first compressor (1) to start a new thermodynamic cycle. The thermodynamic cycle is repeated many times and will be interrupted by a thermostat (12), which will turn the compressors $(1,6)$ off when the pre-set temperature has been reached. Starting more suitably from point (1), all fluid flow-rate is inserted in the compressor (1), which increases its pressure to a certain level. The fluid is afterwards sent to the second compressor (6) which further raises the pressure to such a value that the corresponding saturation temperature is greater than the temperature of the thermal energy tank (3). Through the high-pressure exchanger (2), the working fluid is taken to the status of saturated liquid or liquid under cooled by some degree Celsius. When going out of the condenser (2), a certain liquid flow-rate is bled and laminated through a thermostatic valve (4) getting cooled and being taken to an intermediate pressure. Then, it enters the economizer (5), receiving thermal power by the remaining fluid flow-rate going out of the condenser (2) which decreases its temperature, getting further under cooled. The initially bled flow-rate, at a status of low-title steam, completely evaporates, going to the overheated steam status; then, it is expanded through the component (7) till a second intermediate pressure level. The bleeding degree is suitably calibrated in order to guarantee the complete evaporation of the bled flow-rate, a certain pinch to the heat exchanger (5) and that simultaneously fluid going out of the expander is at a minimum saturated steam. The recovered mechanical energy is converted into electric energy through an alternator (8), is accumulated and delivered to the compressor (1), guaranteeing the chance of an autonomous adaption to different load condition without the help of external checks. The accumulation is performed through a suitable device, which is moderately regenerated after every cycle of use. The not bled flow-rate is inserted in the thermostatic expansion valve (9) and expanded till the evaporation pressure; afterwards, it is completely evaporated through the low-pressure exchanger, evaporator (10), then absorbing thermal power from the thermal source (11). The working fluid, at its overheated steam status, is then taken to the second intermediate pressure level, namely at the same outlet pressure from the expander (7), through the compressor (1); after the first compression, the fluid is remixed with the bled flow-rate to start a new thermodynamic cycle. The basic electric diagram of a thermal operating machine according to the present invention is show in figure (f).

\section{Electric diagram Proposed}

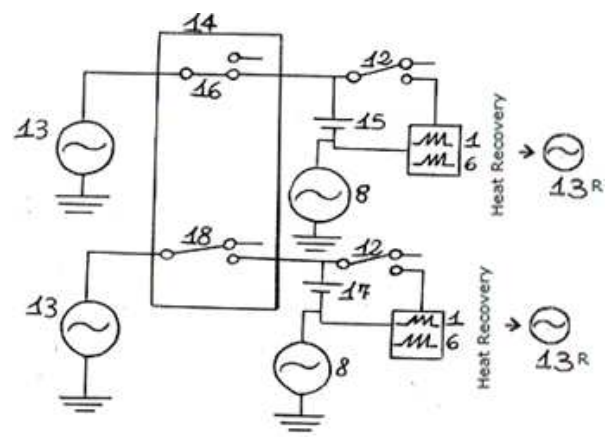

Figure (f)

It is based on the use of a source aimed to transmit electricity. A voltage generator (13) to supply the first compressor supplies the compressor $(1,6)$. Turning the operating compressors $(1,6)$ on and off are duly controlled by the thermostat (12). An automatic timed control system for switching the electric circuit off, namely a time-varying device (14) which opens and closes the electric circuit of the plant, allows managing the operation of an electric charge accumulator $(15,17)$ present inside the plant as re-usable source of electric energy $(15)$, or as electricity generator $(17)$. 
When the switch is closed (16), the accumulator (15) charge is moderately re-established, through the application of adequate electric energy supplied by the source (13) aimed to use and transmit electricity, depending on hourly production and consumption slots, namely when the demand and offer laws for electric energy are capable of enabling a sustainable development, or as electricity generator (17), namely when the switch (18) is open, capable of delivering electric energy to the plant when the hourly slot corresponds to the load peak of the mains, or without supply from the electric mains (13), for example caused by a malfunction or by a failure. Charging and discharging steps occur depending on hourly production and consumption slots. The electric energy generated by the alternator (8) and by the thermoelectric generator (13r) can anyway be stored in the accumulator $(15,17)$ and be used afterwards, when needed. Due to readability and compactness reasons, in the electric diagram of figure (f) the connection to a rectified downstream of the alternator (8) has been omitted, the rectified allowing to suitably accumulate direct current electric energy, and to an inverter downstream of the accumulator $(15,17)$ which would allow correctly delivering alternate current electric energy to the compressors $(1,6)$.

\section{Supplementary Materials}

Table 8: Reference Thermodynamic Values of a Traditional Plant

\begin{tabular}{|c|c|c|c|c|c|c|}
\hline Refrigerant & GWP100 & $\begin{array}{c}\text { Cooling } \\
\text { Capacity }\end{array}$ & $\begin{array}{c}\text { Condensation } \\
\text { Temperature }\end{array}$ & $\begin{array}{c}\text { Evaporation } \\
\text { Temperature }\end{array}$ & $\begin{array}{c}\eta_{\mathrm{C}} \\
\text { (Compression } \\
\text { Efficiency) }\end{array}$ & Mass Flow \\
\hline $\mathrm{R} 404 \mathrm{a}$ & 3922 & $30 \mathrm{~kW}$ & $45{ }^{\circ} \mathrm{C}$ & $-45^{\circ} \mathrm{C}$ & 0,53 & $0,39 \frac{\mathrm{kg}}{\mathrm{s}}$ \\
\hline
\end{tabular}

Table 9: Reference Thermodynamic Values of a Thermal Operating Machine according to the Present Invention

\begin{tabular}{|c|c|c|c|c|c|c|c|}
\hline Refrigerant & GWP100 & $\begin{array}{c}\text { Cooling } \\
\text { Capacity }\end{array}$ & $\begin{array}{c}\text { Condensation } \\
\text { Temperature }\end{array}$ & $\begin{array}{c}\text { Evaporation } \\
\text { Temperature }\end{array}$ & $\begin{array}{c}\boldsymbol{\eta} \mathbf{C}(\mathbf{1}) \\
\text { (Compression } \\
\text { Efficiency) }\end{array}$ & $\begin{array}{c}\boldsymbol{\eta} \mathbf{C}(6) \\
\text { (Compression } \\
\text { Efficiency) }\end{array}$ & $\begin{array}{c}\eta \mathbf{t} \\
\text { (Expansion } \\
\text { Efficiency) }\end{array}$ \\
\hline $\mathrm{R} 404 \mathrm{a}$ & 3922 & $30 \mathrm{~kW}$ & $45^{\circ} \mathrm{C}$ & $-45^{\circ} \mathrm{C}$ & 0,51 & 0,71 & 0,69 \\
\hline
\end{tabular}

Table 10: Industrial Tariff Plan for Italy

\begin{tabular}{|c|c|}
\hline $\begin{array}{c}\text { Peak band: } \\
\text { Monday to Friday from 8 a.m. to 7 p.m. }\end{array}$ & $0,068 \frac{€}{\mathrm{kWh}}$ \\
\hline $\begin{array}{c}\text { Off-Peak band: } \\
\text { Weekends, holidays and daily from 7 p.m. to 8:00 a.m. }\end{array}$ & $0,048 \frac{€}{\mathrm{kWh}}$ \\
\hline $\begin{array}{c}\text { Electric energy cost for Counter Transport and Management } \\
\text { (CV) }\end{array}$ & $0,083 \frac{€}{\mathrm{kWh}}$ \\
\hline $\begin{array}{c}\text { Electric power cost for transport and management (CP) } \\
\text { Fixed Cost for Transport and Counter Management, System } \\
\text { Charges and Energy (CF) }\end{array}$ & $30,073\left(\frac{\frac{€}{\mathrm{~kW}}}{\text { year }}\right)$ \\
\hline
\end{tabular}

Table 11: Operating Data for the Year 2017

\begin{tabular}{|c|c|c|c|c|c|}
\hline $\begin{array}{c}\text { Annual } \\
\text { Operation of } \\
\text { the Compressor } \\
\text { in the off-Peak } \\
\text { Band } \\
\text { (hourFA) }\end{array}$ & $\begin{array}{c}\text { Annual } \\
\text { Operation of } \\
\text { the Compressor } \\
\text { in the Peak } \\
\text { Band } \\
\text { (hourFB) }\end{array}$ & $\begin{array}{c}\text { Annual } \\
\text { Operation of } \\
\text { the Compressor } \\
\text { (Fmc) }\end{array}$ & $\begin{array}{c}\text { Industrial Tariff } \\
\text { Plan for Italy in } \\
\text { the Peak Band } \\
\text { (TFA) }\end{array}$ & $\begin{array}{c}\text { Industrial Tariff } \\
\text { Plan for Italy in the } \\
\text { off-Peak Band } \\
\text { (TFB and cE) }\end{array}$ & $\begin{array}{c}\text { Average } \\
\text { Hourly Rate } \\
\text { (cEAN) }\end{array}$ \\
\hline 1446 hours & 2934 hours & 4380 hours & $0,068 \frac{€}{k W h}$ & $0,048 \frac{€}{k W h}$ & $0,055 \frac{€}{k W h}$ \\
\hline
\end{tabular}


Average hourly rate $=\frac{(\text { hour } F B * T F B)+(\text { hour } F A * T F A)}{F m c}$

\section{REFERENCES}

1. Giuseppe Verde, A novel configuration layout for a vapor compression reverse cycle. J. Fundam. Appl. Sci., 2017, 9(1S), 1211-1224.

2. Giuseppe Verde, Impianto Termodinamico Operatore - National Patent n.NA2015A000017 (2015, Italy).

3. Giuseppe Verde, Thermal Operating Machine - International Patent n.PCT/IT2017/000071 (2016, Italy).

4. G.F. Hundy, A.R. Trott, T.C. Welch, Refrigeration and Air Conditioning (Fourth Edition), Expansion valves, p.103.

5. Michael J. Moran, Howard N. Shapiro, Fundamentals of Engineering Thermodynamics (Fifth Edition), Refrigeration and Heat Pump Systems, p.457. 
